\title{
Repatriation Adjustment Problems and the Successful Reintegration of Expatriates and Their Families
}

\author{
Aaron W. Andreason \\ University of Montana - Missoula \\ Kevin D. Kinneer \\ University of Michigan
}

\begin{abstract}
Many firms have not made special efforts for their repatriates despite growing evidence indicating high levels of dissatisfaction and high attrition rates because of problems encountered in repatriation adjustment. This paper discusses the nature of these problems and the reasons why such efforts are typically not made. It further describes a theoretical framework, combining adjustment and individual control theories, which can be used to analyze and integrate recent research. Based on this theoretical framework and recent research findings, recommendations are made for future research and for managing reintegration into the home culture and organization.
\end{abstract}

\section{Introduction}

It seems all too soon that the foreign assignment is over and that expatriates and their families are returning home. To their great surprise, however, many soon discover that they are returning neither to the home they had remembered nor to the homecoming they had anticipated (Brislin \& Van Buren, 1974). Expatriate managers themselves often find that their careers have been in a holding pattern while others have been promoted ahead of them. What is more, these expatriates and their families have often changed in ways that make it difficult for them to readjust to their home and organizational culture (Black, 1992) and for home organization management to accept their returning managers. The home country and organization may have also changed in important ways during their absence (Black, 1992).

Repatriation or cross-cultural re-entry is the transition from the foreign country back into the home country and organization. Upon return repatriates often experience problems similar to those encountered in initial cross-cultural entry into the foreign environment. These involve readjusting to the home country work and nonwork environments as well as interacting again with home country nationals (Black, Gregersen, \& Mendenhall, 1992). Until the 1980s, international firms had considered re-entry to be a relatively easy process and it is clear that very few firms had developed definitive transition strategies for their returning managers. After all, what was there to adjust to? They were returning home, weren't they? However, mounting empirical and anecdotal evidence has demonstrated that re-entry is in fact a major problem, presenting expatriates and their families with new and often unanticipated challenges, to the extent that repatriation is sometimes referred to as reverse or re-entry culture shock (Murray, 1973).

Repatriation is such a problem that it keeps many returning managers and their spouses from accepting a second overseas assignment (Copeland \& Griggs, 1985). 
Adler (1981), for example, found that for many individuals the process of readjustment to being back home was even more difficult than the initial adjustment to living overseas. As a consequence, the average attrition rate within one year after repatriation ranges between 15 and 25 percent with subsequently nearly 40 percent leaving within three years (Grant, 1997; O' Boyle, 1989). Yet, despite a growing concern with these high attrition rates, international firms still do not appear to be paying a great deal of attention to the problems of repatriation adjustment. It seems further that many firms are either ignorant of and/or unconcerned about the growing number of reports of repatriation problems, thereby increasing the probability of making the same mistakes as their predecessors.

It is little wonder then that some studies (e.g., Gomez-Mejia \& Balkin, 1987) report that a majority of repatriated employees are dissatisfied with the repatriation process. The result is a significant loss of both investment funds and international expertise for these firms. It has been further demonstrated that a firm's repatriation failures may affect its ability to attract future expatriates (Welch, 1994). These and other often-cited repatriation adjustment problems have become the drivers behind this still underresearched aspect of the expatriate experience. The purpose of this paper is to: (1) discuss the reasons why many firms do not have effective repatriation programs, (2) analyze the dynamics of repatriation problems and the study of their antecedent variables within the framework of uncertainty reduction, and (3) discuss the implications these findings have for re-entry management programs.

\section{Why Companies Do Not Make Special Efforts for Repatriates}

In a survey conducted by Harvey (1989), the most frequently mentioned reasons why firms lack repatriation training programs were: a lack of expertise in establishing such programs (47 percent), the cost of the programs (36 percent), and the belief by top management that such programs were not needed (35 percent). As an explanation for the last of these reasons, Dowling, Welch and Schuler (1999) point out that top management may not see that such programs are needed because repatriation problems are not as dramatic, visible, or readily identifiable as expensive as are expatriation problems.

An often mentioned reason for the ignorance and/or lack of concern of many firms regarding repatriation problems is the out-of-sight, out-of-mind syndrome, a frequently observed phenomenon in which repatriates return to organizations that appear to have forgotten who they are, do not know what they have accomplished during their overseas assignment, and do not know how to use their international knowledge appropriately (Solomon, 1995). This is obviously another manifestation of the continuing parochialism on the part of business executives who seem to believe that modern business practices are similar enough around the world that it is not necessary to engage in special efforts for their expatriates (Black \& Gregersen, 1999). How much easier is it, however, to make this erroneous assumption when expatriates are merely returning home? 
Another reason may be a difference of perception between international firms and expatriates regarding the motivations and expectations connected with cross-cultural transfers. Paik, Segaud and Malinowski (2002), for example, found that the expatriate accepts the assignment anticipating career advancement and adventure, whereas the firm is more likely to send the expatriate abroad to transfer the corporate culture and meet project objectives. In addition, repatriates are more likely to place greater value on reintegration into the home country culture upon return while the firm places greater value on reintegration of the expatriate into the corporate culture. The implication of these findings is that firms do not understand the contrasting expectations of their returning expatriates and are, therefore, less likely to provide the support necessary for a smooth transition.

Finally, Black et al. (1992) point out that, from a theoretical perspective, the lack of systematic investigation of repatriation adjustment by scholars may stem, in part, from an underlying assumption that repatriation adjustment is not significantly different from either adjustment after a domestic relocation transfer or from adjustment to an overseas assignment. This is similar to the erroneous assumption, previously mentioned, made by executives who do not believe that they need to make special efforts for their expatriates because they are merely returning home. An understanding of repatriation adjustment should, therefore, begin with a comparison between repatriation and other job-related geographic transfers.

\section{Toward a Theoretical Framework}

\section{$\underline{\text { Repatriation as Compared with Other Job-Related Geographic Transfers }}$}

In proposing a theoretical framework for repatriation research, Black et al. (1992) initially compare repatriation with two other kinds of geographic transfers: domestic relocation and expatriate transfers. First, in comparison with a domestic relocation transfer (such as moving across the country), repatriation adjustment differs both in degree (with regard to the level of novelty on the new job) and kind, since repatriation involves a return to one's home country after what may often be an extended period of absence and domestic relocation merely involves an in-country transfer. The result is that these two types of adjustment are sufficiently different from each other, such that variables that play a minor role in domestic relocation adjustment may actually play a critical role in repatriation adjustment (Black et al., 1992).

Second, when comparing expatriate transfers with repatriation transfers, Black et al. (1992) argue that while both involve a movement between countries (thus, involving a similar range of novelty), in expatriate adjustment cognitive expectations are based primarily on vicarious experience (e.g., training or other sources of information) or on simple stereotypes in anticipation of the transfer. This more indirect experience is likely to lead to flexible expectations because the expatriate is unsure of what to expect. Repatriates, on the other hand, have had actual personal experience with their home countries and this more direct form of experience is more likely to lead to more rigid expectations (i.e., repatriates already believe that they are sufficiently knowledgeable) 
and when they return home they are, therefore, unprepared for the changes that have occurred. Indeed, a major obstacle to the readjustment process is the need for such readjustment is so unexpected, by repatriates as well as by their home organizations.

\section{$\underline{\text { Suggested Theoretical Foundations for Repatriation Adjustment }}$}

A few emerging theories explain various aspects of the problems experienced by repatriates and their families. In their review of proposed theoretical explanations regarding the overall readjustment process, Black et al. (1992) point out that adjustment theorists, studying domestic relocation adjustment, as well as researchers in the area of expatriation adjustment assert that moving into a new environment creates uncertainty and thereby a breakdown of an individual's interpretation systems. This, in turn, creates a need to reduce that uncertainty. A related explanation is proposed by individual control theorists who argue that individuals placed in new and unfamiliar environments have a need to reestablish a certain level of control. According to this latter model, two types of control can occur. The first is predictive control, which is defined as the ability to make sense of, or predict, one's environment in terms of how one is expected to behave and in terms of the rewards and punishments (i.e., negative consequences) that are associated with specific behaviors. The second is behavioral control, which is defined as the ability to control one's own behaviors that have an important impact on the environment, and, by extension, as an indirect attempt at environmental or outcome control (Bell \& Staw, 1989).

A logical integration of adjustment and control theory as suggested by Black et al. (1992) can be stated as follows: (1) Individuals establish behavioral routines based on their perceptions of expectations, reward and punishment (i.e., negative incentive) contingencies, and preferences for preferred outcomes. (2) When confronted with new and unfamiliar situations, established routines are broken and the individual's sense of control is reduced. (3) Individuals subsequently attempt to reestablish control by reducing uncertainty in the new situation through predictive and/or behavioral control. A first step in reducing uncertainty is the formation of expectations about the new situation. (4) In consequence, those factors that reduce uncertainty would facilitate adjustment, while those factors that increase uncertainty would inhibit adjustment.

One implication of this combined theoretical model is that, not only will individuals need to make adjustments when actually placed in a new environment (in-country adjustment) but, unless entering the new environment is totally without warning, they can also make some anticipatory adjustments. Another implication is that adjustments can be effective and uncertainty can be reduced only if they are based on accurate or met expectations, as opposed to inaccurate or unmet expectations. Indeed, many recent studies have attributed the failure in reintegrating into the back-home organization to a discrepancy between re-entry expectations and the reality that returning expatriates encounter upon return (Hammer, Hart, \& Rogan, 1998; Stroh, Gregersen, \& Black, 1998). 


\section{A Multifaceted Research Approach}

Since research on expatriate adjustment has been underway for a longer period of time, a focus on the commonalities as well as the differences between the expatriate experience and repatriation adjustment can serve as a guide for repatriation research. As an example, research by Shaffer, Harrison, and Gilley (1991) demonstrated that expatriate adjustment is composed of at least three related yet separate facets or dimensions, originally conceptualized by Black, Mendenhall, and Oddou (1991) as (1) adjustment to work, (2) adjustment to interacting with individuals in the foreign country (socializing with host-country nationals), and (3) adjustment to the general environment and culture (living conditions abroad). Further research (e.g., Black \& Stephens, 1989; Gregersen \& Black, 1990) has found that while some antecedent variables affect all three facets of expatriation adjustment, others may have a significant impact on only one facet.

Black and Gregersen (1991) have extended this model to repatriation adjustment research and have found evidence that repatriation adjustment is also multifaceted, involving the same kinds of related yet distinct facets that have been associated with expatriation adjustment. A study by Suustari and Välimaa (2002), however, suggests that, in the case of repatriation adjustment, the work adjustment facet may actually consist of two separate facets or dimensions: job adjustment and organizational adjustment. The result is a total of four different facets or dimensions of repatriation adjustment instead of the three previously suggested in the literature. One way to conceptualize repatriation adjustment, therefore, is that the general and interactions adjustment facets may be categorized as dealing with the personal readjustment of expatriates and their families; job and organizational adjustment facets may be categorized as dealing with the professional (work-related) readjustment.

Just as with expatriate research, Black et al. (1992) assert that the likelihood that repatriation adjustment is multifaceted is important because it allows for the possibility that: (1) various antecedent variables may be related to all facets of adjustment or only to specific factors, and (2) that certain facets may be more or less significantly related to the observed outcomes (or problems) of repatriation adjustment. Much of current research may, therefore, be directed toward determining (1) what these key antecedent variables are with regard to how expectations are created, (2) how these variables affect the various facets of expatriation adjustment, and (3) how these variables influence the frequently occurring outcomes or problems of repatriation adjustment.

The first step in integrating current research should be to review the frequently observed adjustment problems associated with personal and professional repatriation adjustment in light of the formation of expectations and uncertainty reduction. If it serves no other purpose, such a review can aid repatriates, their families and their home organizations in becoming aware of these problems and thus be able to make some of the necessary anticipatory adjustments. Such information is also helpful in determining how well extant models explain these problems or, alternatively, where there may be a 
need for further theoretical explanations and research beyond the previously mentioned theories of overall adjustment.

\section{Problems Encountered in Repatriation Adjustment}

\section{Personal Readjustment Problems}

The causes of personal re-entry readjustment problems are to a certain extent inherent in having had to adjust to living in a foreign culture for a period of time. With regard to general adjustment, as an example, repatriates and their family members frequently report experiencing a comedown upon return because of having developed inaccurate expectations in the form of fond memories and myths about the general environment and culture of their home country while abroad. Adler (2002) speculates that this may occur because when expatriates are experiencing the trauma of culture shock in a foreign assignment they "... often idealize their home country, remembering only the good aspects of home - in essence creating something to hold onto and dream about." The resulting inaccurate expectations create two types of gaps: the gap between the way it was and the way it is, and the gap between idealized memories and reality. The disappointment that occurs when these unrealistic expectations are not metcan be overwhelming. Most returnees, as a consequence, express surprise not only with regard to their own feelings but also with reality, and are reluctant to even talk about it because they think that something is inherently wrong with themselves.

Another source of inaccurate expectations and subsequent reality shock involves giving up the personal and economic advantages of the foreign assignment. As Dowling and Welch (2005, page \#) point out, "Usually, at least for PCNs, the international assignment is a form of promotion. It carries greater autonomy, a broader area of responsibility (because of the smaller size of the overseas subsidiary) and, at the top management level, a prominent role in the local community. The result is higher status. Some expatriates use the term kingpin to describe their positions abroad. Upon return the repatriate is expected to resume his or her position within the home company, with the loss of status and autonomy." (This direct quote is quite long. Is it necessary?) Family members, too, may be reluctant to give up their special status. In some countries, for example, expatriate families have servants, and the assignment may involve interaction with the social and economic elite as well as a variety of sophisticated international managers. The return home, however, may bring with it feelings of social disappointment due to a loss of status and self-esteem. Compounding the loss of the personal advantages is a corresponding loss of many economic advantages present in the foreign assignment, including such benefits as cost of living allowances, foreign service premiums, housing subsidies, education allowances and other related benefits. Some repatriates, in addition, may no longer be able to afford to buy a home similar to the one sold a few years before (Dowling \& Welch, 2005). This difficulty in giving up the economic lifestyle of the foreign assignment may result in ineffective coping strategies upon return, explaining in part why some repatriates become financially over-extended. 
As previously indicated, many repatriates are surprised by the unexpected amount of change that has occurred during the foreign assignment (Black et al., 1992). The ability of repatriates to slip easily back into their previous lifestyles may be thwarted because during this period of absence certain aspects of the individual (e.g., attitudes, values, habits) are likely to have changed. When expatriates return, they are not really the same persons. Living in another country for an extended period of time is a major influence on personality change, and it is likely that while abroad expatriates and their family members have taken on some of the values of the host culture. This may be particularly a problem for expatriates who have "gone native"; that is, those who have adapted well to the foreign culture and have developed a high level of commitment to the foreign operation but a low commitment to the parent firm (Black \& Gregersen, 1992). Subsequently, these repatriates may find it difficult to readjust to their own cultures and organizations. It is also likely that a variety of elements in the home country (e.g., technology, social norms, organizational culture, organizational communication channels, economic conditions, styles of dress, aspects of the language) have changed in ways not anticipated by returnees. "It is as if they had pressed the 'pause' button as they flew out of the country and expected life at home to remain in 'freeze frame"' (Dowling \& Welch, 2005). Furthermore, these changes may have occurred relatively independently of each other, and unlike the manager who has remained in the home country, the repatriating manager is less likely to have examined the interplay between his or her own personal changes and the changes in the home country. Home country organizations also may not anticipate changes in their expatriate managers. The problem is that these changes suddenly confront each other upon return; explaining why, as Black et al. (1992) point out, most repatriates report re-entry as being more difficult than the initial move overseas. The out-of-sight, out-of-mind attitude that most firms take enhances this discrepancy. According to Adler (2002), returnees, therefore, frequently describe stages of adjustment upon return which are similar to those experienced in initial culture shock abroad, including an initial high mood followed by a low period.

With regard to interactions adjustment, Copeland and Griggs (1985) report that contrary to expectations, "Virtually everyone who returns is shocked by the lack of interest of people at home. Friends say, 'I'm dying to hear all about Indonesia,' but soon they switch the subject to last weekend's football game. Returnees need to talk about their experience - a major event in their lives - yet no one will listen... If you talk about your overseas experience, people don't know how to relate to you - you don't fit in." To compound this problem, returnees find that the changes that have occurred at home have put them out of touch with their home culture such that they often feel like foreigners in their own country. Thus, readjustment unexpectedly takes on many aspects similar to entry into a foreign culture. "Children in particular have a hard time. They are different, more sophisticated, literally more worldly than children who have not left their home country. At the same time, they may feel odd not knowing the latest slang, rock and television stars, or ways to dress." (Copeland and Griggs, 1985). Subsequently, they are also likely to have difficulty in gaining the acceptance of peer groups. 
Similar to what may have occurred during the low period of adjustment abroad, in reverse culture shock family members may begin to create a false comparison by glamorizing the life they left behind in the foreign country (Dowling \& Welch, 2005). They may even express a desire to return. In comparison, life back home now seems dull and unexciting. Unlike the situation in the foreign assignment, repatriates most often find a significant lack of the kinds of support networks they found overseas. As a contrast, since adjustment problems are anticipated in the foreign assignment, international firms are beginning to provide direct support for their expatriates in the form of organization-sponsored programs to assist in the adjustment process (e.g., predeparture training, in-country training, mentor systems) and indirect support in the form of organization-encouraged activities and techniques (e.g., joining international clubs, developing hobbies). These on-assignment support networks aid expatriates and their families in developing effective coping skills (Andreason, 2003). But because neither the international firm nor the employee are expecting adjustment problems upon return, comparable forms of support are conspicuously absent.

\section{Professional Readjustment Problems}

It has been reported (e.g., Black \& Gregersen, 1991) that for some repatriates professional readjustment problems can be even more debilitating than personal readjustment problems. To a great extent one can argue, however, that repatriation adjustment is a global factor such that the professional facets of repatriation adjustment are not truly independent from the previously discussed facets of personal readjustment. All facets of one's life tend to interact. Brett and Stroh (1992), for example, have found that the reverse culture shock experienced by family members can interfere with the ability of returning expatriates to resume their responsibilities at the home office. Thus, models of overall adjustment need to be applicable to both personal and professional readjustment and any review of the frequently cited problems connected with professional adjustment must take this interaction into account.

In professional readjustment, repatriates must adjust or readjust to the job they will be performing. As previously indicated, a major reason why managers accept an international assignment is the expectation of beneficial effects to their career path. Upon return, however, many find that because of the out-of-sight, out-of-mind syndrome, their careers have actually been in a "holding pattern" and that others have been promoted ahead of them (Feldman, 1991; Harvey, 1989). This can result in significant career disappointment. Additional causes for career-advancement problems may range from organizational downsizing to poor company planning. The bottom line is that repatriates often tend to be placed, at least at first, in mediocre or makeshift jobs (Welch, 1990). Professional re-entry can also be a significant problem for the spouse in the case of dual-career families. If the career path for the trailing spouse was put on hold or altered in some way, negative experiences in job readjustment or job search may affect the partner's feelings of self-worth, compounding the readjustment process and potentially causing tension in the relationship (Dowling \& Welch, 2005). 
The job adjustment problem is exacerbated when, also contrary to expectations, many repatriates receive jobs with less authority, responsibility and autonomy than they were used to in the foreign assignment. In one study, the category of reduced responsibility and autonomy on the job was ranked second, after career advancement, as a major concern upon repatriation (Tung \& Andersen, 1997). As a consequence, other studies (e.g., Barham \& Antal, 1995), not surprisingly, found the re-entry position to be less than their career expectations and less satisfying than their global assignment. In addition, the sense of self-efficacy (a confidence and belief that one can gain control) achieved in the foreign assignment (Dowling \& Welch, 2005) is shattered upon return. Thus, not only must repatriates and their family members make personal adjustments connected with reduced social status upon return, but they must also adjust to a situation of reduced job status and autonomy. The implicit message communicated to a firm's personnel by these kinds of problems, therefore, is that accepting an international assignment is a high-risk career strategy - one that may have a significantly negative impact both on one's career path and also on the nature on one's job (Welch, 1997). Such unmet expectations will likely affect the repatriate's adjustment, productivity, and commitment to the firm. What is more, reports of such problems may also be a general deterrent in a firm's ability to recruit high-caliber personnel for future assignments.

In addition to job readjustment problems, the transition from one organizational culture to another can be difficult and stressful. For one thing, it is likely that in their absence there have been changes in the organizational culture, so previous expectations regarding correct attitudes and behaviors may also have changed. For another, expatriates often return to organizations that do not seem to either appreciate or exploit their newly gained international expertise. This devaluing of the expatriate experience is reflected in the comment of an Australian repatriate: "You gain a lot of expertise, but it's dismissed here" (Welch, 1994). Consequently, repatriates often feel overqualified for their positions and become an underutilized resource for the organization. Combined with the previously mentioned perceptions of losses in social status, job status, and autonomy, these feelings of underutilization can also have a demoralizing effect.

The research literature also suggests that organizational readjustment problems may occur because the repatriate's role conception may be influenced by that of the foreign assignment; thus, the repatriate's sense-making interpretations may be flawed (Louis, 1980). Just as the foreign assignment can bring about changes in one's personal values, operating in a foreign cultural environment may also bring about significant changes in the returnees' conception of appropriate managerial role behavior (GomezMejia \& Galkin, 1987). Thus, role conflict may occur when the repatriate does not resume the expected managerial behavior upon return. According to Baughn (1995), while abroad expatriates may adopt cultural norms and procedures that may no longer match the home country or the home corporate culture.

This role conflict is obviously two-sided, reflecting not only changes in the repatriate, but also a lack of understanding and appreciation of these changes by the home organization. Adler (2002), for example, reports a frequently occurring xenophobic response on the part of many home-country executives who tend to rate those 
returnees as most effective who appear to be the least foreign; that is, those who do not know or use foreign languages, do not have foreign friends, or were not born in a foreign country. Repatriates, additionally, are rated as more effective if they do not explicitly utilize the skills and learnings gained while abroad on their job back home. As a result, many repatriates, according to Selmer (1999), choose a transition strategy of (1) resocialization, in which they neither recognize nor use their globally acquired skills, but distance themselves from their global experience and just try to fit back in. Others, particularly those who believe they cannot fit back in, become (2) alienated and continue to see the foreign societal and organizational culture as better than their own. These are often those who had "gone native" during the foreign assignment and may even want to return. Both of these transition strategies make repatriation readjustment more difficult and prevent firms from utilizing globally acquired skills. A more productive strategy, in contrast is, a (3) proactive strategy in which repatriates reject neither their own nor the foreign culture; rather they combine the best aspects of both and contribute to their firms by creating new, synergistic ways of perceiving and working in their organizations, based on their experiences at home and abroad.

\section{The Search for Relevant Antecedent Variables}

\section{A Preliminary Model}

One of the major thrusts of current research is to discover antecedent variables that relate to repatriation adjustment. These are the factors that either enhance or inhibit the adjustment process. Many of these variables reflect the previously mentioned problems encountered in repatriation adjustment. A study of these antecedent variables can provide, among other things, insight into the nature, magnitude, and causes of the variables that are related to repatriation adjustment. Results also can be analyzed with regard to the model of uncertainty reduction, connected with how each variable contributes to the creation of accurate or inaccurate expectations. A major component of a theoretical framework presented by Black et al. (1992), for example, concerns four such suggested general categories of antecedent variables: (1) individual variables, variables that are a function of individual attitudes, values, needs, or characteristics; (2) job variables; (3) organizational variables; and (4) non-work variables. The propositions of this model are, in turn, dependent upon whether they deal with (1) anticipatory repatriation adjustment and are thus more a function of predictive control and accuracy of expectations; or (2) in-country repatriation adjustment, which emphasizes both predictive and behavioral control; thus involving a more directly experiential test of expectations.

\section{$\underline{\text { Individual Variables }}$}

With regard to anticipatory repatriation adjustment, Black et al. (1992) propose that (1) time overseas immediately preceding the return home, (2) the total time away from the home country over a career, and (3) the magnitude of change in the home country will be negatively related to accurate anticipatory expectations whereas, (4) the frequency and length of visits back to the home country and home office will be positively related 
to all facets of accurate expectations. Of the long list of individual variables that have been asserted to be important to in-country adjustment, from a control theory perspective, Black et al. (1992) propose that (1) a higher than actualized need for control (resulting in greater attempts to gain control), and (2) a high self-efficacy (a confidence and belief that one can gain control) will be positively related to all facets of repatriation adjustment.

\section{$\underline{\text { Job Variables }}$}

In anticipatory repatriation adjustment, Black et al. (1992) propose that: task interdependency between the expatriate and home country operations is expected to increase the exchange of information and thus be positively related to the formation of accurate work expectations. With regard to in-country adjustment they propose that (1) role clarity (the extent to which an individual knows what is expected on the job), and (2) role discretion (the adjustment of the work role to fit the individual) would reduce the level of uncertainty, whereas (3) role conflict (conflicting signals about what is expected in the new work role) would inhibit predictive control and be negatively related to repatriation adjustment.

\section{Organization Variables}

In anticipatory repatriation adjustment, Black et al. (1992) propose that (1) sufficient anticipatory repatriation training regarding work, interacting with home nationals again, and general conditions prior to return would have a positive impact on all aspects of repatriation adjustment, (2) having a home country sponsor (who is responsible for keeping in touch with the expatriate) would be positively related to accurate work expectations, and (3) greater frequency and content of communication between the home office and the subsidiary would also positively affect the formation of accurate repatriation expectations. With regard to in-country repatriation adjustment they propose that the extent of (1) post-return training would have a positive impact on all facets of repatriation adjustment, and that the (2) congruence and clarity of information regarding individual career objectives and repatriation policies (including the likelihood of less autonomy than in the foreign assignment) would be positively related to in-country work adjustment.

\section{$\underline{\text { Non-Work Variables }}$}

With regard to anticipatory repatriation adjustment, Black et al. (1992) propose a negative relation with regard to the cultural distance between the host and the home countries because of the amount of change that was necessary for the individual to adjust to the foreign assignment (the "going native" factor). With regard to in-country repatriation adjustment, they propose that (1) a downward shift in social status and poorer housing conditions will be negatively related to all facets of repatriation adjustment, but that adequate (2) spouse repatriation adjustment will be positively related to expatriate general and interaction repatriation adjustment. 


\section{Examples of Recent Relevant Research}

Recent research has sought to verify the propositions made by the Black et al. (1992) preliminary model and has also begun to look for additional antecedent variables. In a study of Finnish repatriates, for example, Suustari and Välimaa (2002) did find support for the view that repatriation adjustment is a multifaceted phenomenon. Specific findings regarding antecedent variables demonstrate that general adjustment was negatively related to (1) the age of the respondent (a finding that was opposite to what was expected from other models), (2) the length of the foreign assignment, (3) the extent of expatriation adjustment problems in the foreign assignment, and (4) the amount of role conflict. On the other hand, positive correlations were found with (5) the length of time of role negotiations before ending the international assignment, and (6) keeping up on events at home. With regard to organization adjustment, two antecedent variables were found to be positive correlates: (7) the length of time of role negotiations before ending the international assignment and, (8) a willingness to relocate internationally, whereas (9) role conflict was a negative correlate. With regard to job adjustment (10) the length of time or role negotiations before ending the international assignment and (11) the amount of role discretion were positive correlates. With regard to interaction adjustment, (12) the extent of expatriation adjustment problems in the foreign assignment, and (13) role conflicts were negative correlates. In addition to providing support for the multifaceted view of repatriation adjustment, findings (2), (4), (6), (9), (11) and (13), of this study, support specific propositions of the Black et al. (1992) preliminary model while the other findings suggest additional antecedent variables.

Other antecedent variables have also been proposed. Black and Gregersen (1992), for example, have suggested that the type of allegiance expatriates established during the foreign assignment will have an impact, not only on their performance while abroad, but also on their ability to readapt upon return. Those who develop a Dual Allegiance, characterized by a high commitment to both the parent firm and the foreign operation, should have a higher probability of adjusting to their overseas stay, completing their foreign assignment, and staying with the firm upon repatriation than those characterized as Free Agents, Going Native or Hearts at Home.

As another example, O'Sullivan (2002) drawing on Career Transitions Theory and the protean perspective, proposes that some repatriates have an easier time surviving the problems of repatriation adjustment than do others. A protean (proactive) approach suggests that repatriate "survivors" (as opposed to "victims") take more responsibility in actively carving out an appropriate niche for themselves, rather than merely reacting to (making sense of) the niche in which they find themselves. Reactive (symptom-focused) strategies do nothing to change the repatriate's new environment and the stressors within it, whereas proactive strategies such as information-seeking and social networking have been associated with greater adjustment. This study also suggests that expatriates with certain personality characteristics or orientations (i.e., extraversion, conscientiousness, openness to new experience, emotional stability, and agreeableness) will be successful in the use of proactive behaviors in protean-receptive organizational climates which allow such behaviors to occur. 


\section{Suggestions for Future Research}

More research is needed before a definitive model of repatriation adjustment is possible, especially in the area of organizational factors. Black et al. (1992), for example, propose studying the effect of having internationally experienced top management, a longitudinal assessment of the factors that causally impact the various facets of repatriation adjustment over time and whether some variables that are proposed to benefit the repatriation process may actually inhibit the expatriation process or vice versa. Suustari and Välimaa (2002) point out the need for replication of their findings with other national groups and also recommend a comparative study of the adjustment process with those who are more on their own abroad (as many Finns in their sample were) as opposed to those who are transferred by their company. O'Sullivan (2002) suggests further the need for studies to determine what initially triggers an individual's awareness that proactivity might be needed in a given situation. In addition it may be useful to (1) further investigate the personality characteristics of repatriation survivors and the organizational climates which facilitate proactive behaviors, (2) evaluate the effectiveness of various re-entry training programs, and (3) reconcile contradictory findings with regard to salient antecedent variables.

\section{Managing Re-Entry}

Repatriation programs must take into account repatriation adjustment problems reported by practitioners and academics as well as current research regarding their antecedent variables. As has been pointed out, since many studies have attributed failure in reintegrating into the back-home organization to a discrepancy between reentry expectations and reality, the uncertainty reduction model can be used as a theoretical framework for application as well as research. A successful repatriation outcome can be defined as: "...one in which, upon return, the repatriate gains access to a job which recognizes any newly acquired international competencies; experiences minimal cross-cultural readjustment difficulties; and reports low turnover intentions (O'Sullivan, 2002)." Effective repatriation programs provide direct support in the form of organization-sponsored programs that assist in the readjustment and indirect support in the form of organization encouraged individual proactive strategies.

\section{Organization-Sponsored Repatriation Programs}

\section{Predeparture Training for the Foreign Assignment}

The time to begin planning for re-entry is even before leaving for the foreign assignment. Effective pre-departure recruiting and selection procedures, to begin with, can screen out employees and family members with personal characteristics or family situations, which would limit their probability of success, along with those who are unwilling to go on the foreign assignment. This can be followed by thorough predeparture training, as well as effective in-country support programs, since those who experience significant problems during the foreign assignment are also more likely to 
have repatriation adjustment problems. Pre-departure training can also inform those going on the foreign assignment as to what kinds of problems to expect upon return. For repatriates and their family members, who often think that their experience is somewhat unique and that there is something fundamentally wrong with themselves, just knowing what kinds of problems to expect is a useful beginning. Proactive (protean) approaches are more likely if expatriates and repatriates can anticipate the frequently encountered problems.

\section{Providing Assurances}

In addition to informing, there are other ways firms can insure that expectations are met. As previously mentioned, adjustment and individual control theorists point out the needs of reducing uncertainty and establishing control in new environments. One transition strategy suggested for professional re-entry is the use of repatriation agreements, whereby firms give candidates preparing for international assignments written guarantees as to the length of the foreign assignment, expectations regarding job performance while abroad, and, upon return, that a mutually acceptable position will be available. In the absence of such agreements, repatriate professional expectations may not be met and there may be a perceived breach of the psychological contract believed to be implicit in the international assignment (Dowling et al., 1999).

\section{Formal Programs}

Formal repatriation programs, to begin with, deal with anticipatory adjustments and start several months before returning home. In addition to the use of repatriation agreements, firms can create accurate expectations and thus ameliorate the problems of professional and personal re-entry by (1) establishing home leave policies that allow the expatriate to maintain professional contact via occasional visits back to the home organization and family members to keep up with changes at home, (2) selecting a home office executive to be a sponsor or mentor who will represent the interests of the expatriate while away on assignment and assist him or her in the repatriation process, and (3) establishing policies and procedures that assess and utilize skills gained on the foreign assignment. Post-return programs can help repatriates and their family members meet expectations via (1) re-entry debriefings with attempt to validate the expatriate experience by learning about new skills gained while abroad, (2) personal and career counseling, (3) relocation assistance, (4) financial assistance, (5) finding schooling for the children, (5) training in workplace changes, (6) stress management, and (7) providing career counseling and job assistance for the spouse.

\section{Organization-Encouraged Individual Proactive Strategies}

There are many things repatriates and their families can and should do for themselves. One problem preventing individual proactive behaviors is that repatriates may not be aware of or prepared to use effective coping strategies; such as information seeking and social networking. Another problem is that the organizational climate may impede individual initiative in utilizing proactive coping strategies. To begin with, therefore, 
O'Sullivan (2002) suggests that organizations establish a protean-receptive organizational climate that will facilitate proactivity by permitting individual searches for appropriate post-return positions, providing proactive training, setting up a useful organizational performance appraisal system (such as performance coaching), providing considerable job discretion, and providing support for protean approaches by senior line management.

With the availability of a proactive (protean-receptive) climate, expatriates and their family members can be made aware of and have more discretion in utilizing additional anticipatory and in-country adjustment coping strategies, which will allow them to manage their expectations. In order to ease re-entry, for example, repatriates and their family members can be encouraged to take an active role themselves in staying in contact with the home organization, keeping informed with regard to changes in technology and company structure and informing the home organization, in turn, regarding their own accomplishments and the skills they have learned while on assignment. Expats and family members also can be encouraged to keep up with changes at home by staying in touch with friends and by keeping up with national events through subscriptions to home country newspapers, magazines, and/or through online news sources. Repatriates can also be encouraged to clarify their own expectations, keeping in mind the two realities - that of the foreign assignment and that of the home organization and country. Basically, repatriates need to prepare for re-entry as extensively as they had prepared for the foreign assignment. This includes doing their homework on job assignments, living conditions, and schooling options. Repatriates can be encouraged to distil the foreign-assignment experiences to be communicated to others into a few specific areas of importance. Finally, in addition to professional networking, repatriates can be encouraged to actively seek out friends and social contacts, in contrast to the foreign assignment where the trend was for others to seek them out.

\section{Conclusion}

More and more, repatriation is being seen as the final link in an integrated, circular process that connects the initial recruitment, selection, and cross-cultural entry of expatriates (along with their family members) with adequate in-country support, and finally, with successful reintegration into the country and organization. Organizationencouraged individual proactive strategies along with organization-sponsored programs can help minimize inaccurate and unmet expectations that seem to be a key to the problems of repatriation adjustment.

With enough insight and preparation, those on foreign assignments can have an enjoyable and productive experience abroad, along with a relatively smooth transition back home. The international firm, in turn, can reap the benefits of the acquiring more global experience and developing a cadre of effective international managers. 


\section{References}

Adler, N. (1981). Re-entry: Managing cross-cultural transitions. Group and Organizational Studies, 6(3), 3418356.

Adler, N. (2002). International dimensions of organizational behavior (4th ed.). Mason, $\mathrm{OH}$ : South-Western.

Andreason, A. W. (2003). Direct and indirect forms of in-country support for expatriates and their families as a means of reducing premature returns and improving job performance. International Journal of Management, 20(4), 548-555.

Barham, K., \& Antal, A. B. (1995). Competencies for the pan-European manager. In P. Kirkbride (Ed.), Human resource management in Europe (pp. 221-241). London: Routledge.

Baughn, C. (1995). Personal and organizational factors associated with effective repatriation. In Jan Selmer (Ed.), Expatriate management: New ideas for international business (pp. 215-230). Westport, CT: Quorum Books.

Bell, N., \& Staw, B. (1989). People as sculptors versus sculpture: the role of personality and personal control in organizations. in Arthur, M. B., Hall, D. T., \& Lawrence, B. S. (Eds), Handbook of career theory (pp. 232-251). Cambridge, UK: Cambridge University Press.

Black, J. S. (1992). Coming home: the relationship of expatriate expectations with repatriation and job performance. Human Relations, 45(2), 177-186.

Black, J. S., \& Gregersen, H. B. (1991). When Yankee comes home: Factors related to expatriate and spouse adjustment. Journal of International Business Studies, 22(4), 671-695.

Black, J. S., \& Gregersen, H. B. (1992). Serving two masters: managing the dual allegiance of expatriate employees. Sloan Management Review, 33(2), 61-71.

Black, J. S., Gregersen, H. B., \& Mendenhall, M. E. (1992). Toward a theoretical framework of repatriation adjustment. Journal of International Business Studies, 23(4), 737-760.

Black, J. S., \& Gregersen, H. B. (1999, March/April). The right way to manage expats. Harvard Business Review, 52-62.

Black, J. S., \& Stephens, G. (1989). The influence of the spouse on American expatriate adjustment in overseas assignments. Journal of Management, 15, 529-544. 
Black, J. S., Mendenhall, M. E., \& Oddou, G. (1991). Toward a comprehensive model of international adjustment: an integration of multiple theoretical perspectives. Academy of Management Review, 16, 291-317.

Brett, J. M., \& Stroh, L. (1992). Job transfer. In Cooper, C. L. and Robinson, I. T. (Eds.), International Review of Industrial and Organizational Psychology (pp. 323-362).

Chicester: John Wiley \& Sons.

Brislin, R. W., \& Van Buren, H. (1974). Can they go home again? International Educational and Cultural Exchange, 1(4), 57-65.

Copeland, L., \& Griggs, L. (1985). Going international, 204. New York: Random House.

Dowling, P. J., Welch, D. E., \& Schuler, R. R. (1999). International human resource management (3rd ed.). Mason, $\mathrm{OH}$ : South-Western.

Dowling, P. J., \& Welch, D. E. (2005). International human resource management (4th ed.). Mason, $\mathrm{OH}$ : South-Western.

Feldman, D. C. (1991). Repatriate moves as career transitions. Human Resource Management Review, 14(1), 163-178.

Gomez-Mejia, L., \& Balkin, D. B. (1987). The determinants of managerial satisfaction with the expatriation and repatriation process. Journal of Management Development, 6(1), 7-17.

Grant, L. (1997, April 14). That overseas job could derail your career. Fortune, 166.

Gregersen, H. B., \& Black, J. S. (1990). A multifaceted approach to expatriate retention in international assignments. Groups and Organizational Studies, 15(4), 461-485.

Hammer, M., Hart, W., \& Rogan, R. (1998). Can you go home again? An analysis of the repatriation of corporate managers and spouses. Management International Review, 38(1), 67-86.

Harvey, M. (1989). Repatriation and career system; an empirical study. Journal Business Studies, 20(1), 131-144.

Louis, M. R. (1980). Career transitions: varieties and commonalities, Academy of Management Review, 5(3), 329-340.

Murray, J. A. (1973). International personnel repatriation: Cultural shock in reverse. MSU Business Topic, 21(2), 59-66. 
O'Boyle, T. (1989, December 11). Grappling with the expatriate issue. The Wall Street Journal, p. B1.

O'Sullivan, S. L. (2002). The protean approach to managing repatriate transitions, International Journal of Manpower, 23(7), 597-616.

Paik, Y., Segaud, B., \& Malinowski, C. (2002). How to improve repatriation management: Are motivations and expectations congruent between the company and expatriates? International Journal of Manpower, 23(7), 635-648.

Selmer, J. (1999). Effects of coping strategies on sociocultural and psychological adjustment of Western expatriate managers in the PRC. Journal of World Business, 34(1), 41-51.

Shaffer, M. A, Harrison, D. A., \& Gilley, K. M. (1999). Dimensions, determinants and differences in the expatriate adjustment process. Journal of International Business Studies, 30(3), 557-581.

Solomon, C. (1995, January). Repatriation: up, down or out? Personnel Journal, 28-30, $32-5,37$.

Stroh, L. K., Gregersen, H. B., \& Black, J. S. (1998). Closing the gap: Expectations versus reality among expatriates. Journal of World Business, 33(2), 11-124.

Suustari, V., \& Välimaa, K. (2002). Antecedents of repatriation adjustment: New evidence from Finnish repatriates. International Journal of Manpower, 23(7), 617-634.

Tung, R. L., \& Andersen, A. (1997). Exploring international assignees' viewpoints: A study of the expatriation/repatriation process. Chicago, IL: Arthur Andersen, International Executive Services.

Welch, D. E. (1990). The personnel variable in international operations: A study of expatriate management in Australian companies. Unpublished doctoral thesis, Monash University, Australia.

Welch, D. E. (1997). Determinants of international human resource management. In Dowling, P. J., \& Welch, D. E., International human resource management (4th ed.). Mason, $\mathrm{OH}$ : South-Western.

Welch, D. E. (1994). Determinants of international human resource management and activities: A suggested framework. Journal of Management Studies, 31(2), 139-164. 